\title{
Effects of Total Customer Solutions Strategic Positioning on Organizational Performance in Telecommunication Industry, in Kenya
}

\author{
Jackson Lemomo Ole Kulet ${ }^{1 *}$ Daniel Wanyoike ${ }^{2}$ Joel K Koima ${ }^{3}$
}

1. School of Management, Jomo Kenyatta University of Agriculture and Technology, Kenya, PO box 1063-20100, Nakuru, Kenya

2. School of Management, Jomo Kenyatta University of Agriculture and Technology, Kenya, PO box 1063-20100, Nakuru, Kenya

3. School of Management, Kabarak University, Kenya, PO Private Bag 20157, Nakuru, Kenya

\begin{abstract}
The purpose of this study was to examine the effect of total customer strategic positioning as envisaged in the Delta Model on Organizational performance. The target population consists of 6, 149 front office employees of the four major telecommunication firms in Kenya namely Safaricom, Airtel, Orange and Equitel. The study covered five major cities and towns in Kenya namely Nairobi, Mombasa, Kisumu, Nakuru and Eldoret. Data was collected from 144 respondents drawn from a cross-section of employees specifically those in front office as they are directly involved in the day to day customer service. The response rate of the total questionnaires issued was $83 \%$. A descriptive survey research design was used in this study. Questionnaires were used to collect the data. Analysis of the survey responses was done by means of Statistical Package for Social Sciences (SPSS). Pearson Correlation along with multiple regressions were used in data analysis and the testing of hypotheses. Pearson correlation was used to establish the association between the strategic position and organizational performance. The findings of the study revealed that total customer solution strategic option had a significant coefficient $(\beta=0.295, p$ value= 0.000). This implies that total customer solutions strategic option had a positive significant effect on organization performance. The findings of the research revealed that a change in the government regulations had a positive and very significant effect on the performance of the telecommunication companies in Kenya. This is revealed by the results which shows that there is a weak, positive correlation which is significant $(R=0.358$; $p$-value $<0.05)$ government regulations and organizational performance of telecommunication firms in Kenya. The study concluded that the total customer solution strategic positioning had not only a positive correlation but also significant effect on the organizational performance of the telecommunication companies in Kenya. The study also concluded that with appropriate government regulations the strategic positions studied will enhance organizational performance in the telecommunication industry in Kenya. The study recommends that managers need to focus on the use total customer strategic position in order to achieve a great organizational performance in their respective organizations. To policy makers the study recommends formulations of good and effective government regulations which in turn will enhance organizational performance.
\end{abstract}

Keywords: Total Customer Solution, Strategic positioning, Organizational performance

DOI: $10.7176 / \mathrm{EJBM} / 11-6-13$

\subsection{INTRODUCTION}

The telecommunications trade has fundamentally transformed in the past ten years as more customers with smart devices consume a lot of data and ever more bandwidth. During this phase, operators have stretched their service range and overhauled their pricing strategy to meet volatile demand, while at the same time increasing capital expenditures to emphasize the on-going essentials to upgrade network capabilities. Operator performance varies considerably by region. North American and Asian telecommunication firms have performed better than other sections, profiting from enhanced degree and powerful secular growth opportunities, respectively.

In the meantime, European telecommunications operators share performance has enhanced on expectation of consolidation, while Latin American telecommunication firms have felt the brunt of a deterioration macroeconomic outlook. Whereas numerous players are diversifying their income streams, ensuring that new services deliver strong margins remains challenging. Meanwhile over-the-top (OTT) companies are as well 
increasing the capacity of their contributions, unsettling diverse industry verticals in the course of action. All entities in the digital ecological unit are now in search of innovative points of differentiation in order to take full advantage of their share of customer spending. As a result, issues of competition and collaboration have certainly not been more prominent (Diskaya et al, 2011).

According to Djiofack-Zebaze and Keck (2009) the regulatory quality played a foremost part in bringing down prices and improving access to telecommunications services in Africa. African countries were in the process of rationalizing and liberalizing their telecommunications segment, the industry has for quite sometimes been lagging when compared to the rest of the globe. The right of entry to telecommunications in Africa is still limited notwithstanding recent technological change and economic growth. Here just like other developing regions, telephones lines are more concentrated in the cities while the rural areas have a restricted access. The deprived superiority of communications weighed alongside the other developing states means that the capacity for telecommunications growth in the African continent is enormous. Presently, the segment is largely possessed by the state, nevertheless a number of regimes have embarked on restructuring programs, the majority of which engage two fundamentals one being steady commercialization by unravelling effective administration from state departments and transferring the responsibility for guideline away from state departments to autonomous institutions. One of the alternatives being looked into in the privatization consist of public bids for sale to financial institution, sale to employees, private investors, strategic investors, divestiture and management contracts with foreign operators. Historical connections play a key role in the privatization process whereby privatization ventures are done with operators with whom the countries have historical connections.

The telecommunication industry is growing at rapid speed and this has made the industry undergo various changes. The changes have mainly been due to increased customer requirements, technology revolution and emergency of innovative models and therefore a much more complex, diverse and competitive telecommunications environment, (Chelimo,2012). Despite the fact that the telecommunication segment in the Kenyan market has been operational in an aggressive atmosphere, the organizations have again and again achieved improved expansion not only in customer numbers but also in their asset base. Therefore it is likely that for this organizations to prosper in an aggressive atmosphere they ought to take on strategies to counter and become accustomed to the changes and challenges in their operational atmosphere (Letangule \& Letting, 2012).

Due to the increased competition any telecommunication firm in Kenya that desires to archive superior organizational performance must adopt strategies that position itself in market dominance. What an organization does towards winning and delivering a world class service to its clientele within its market forms the most important first step towards defining strategic positioning. The appeal to the client, contentment of the client and their maintenance is all that constitutes a strong client bonding. The Delta Model type strategy presents a valuable blueprint that can be used in classifying most favourable strategic positioning, as far as attaining client attachments and presents three distinctive strategic positions for accomplishing that purpose, (Hax, 2010).

A firm can make super profits regardless of the common profitability within the market by positioning itself auspiciously within a specific market place comparative to its competitors. Rivalry and financial profitability pressures imply that the organizations must be more and quicker to respond to market thoughtfulness in provisions of their positions (Mokaya, Kanyagia, \& Wagoki, 2012). Organizational performance consists of the definite output or results of a business as calculated alongside its projected outputs in terms of profits. It includes numerous activities that help in creating the aspirations of the business and monitors the growth towards the objective (Johnson et al., 2006).

\subsection{Statement of the Problem}

Telecommunications industry is an industry that undergoes a lot of changes and it's expanding rapidly. These transformations have been determined by rapidly changing customer requirements, technology advancements and emergence of new-fangled models and therefore a much more complex, diverse and competitive telecommunications atmosphere (Chelimo, 2012). Despite the fact that the telecommunication segment in the Kenyan market has continued functioning in a very competitive atmosphere, the organizations have time and again managed to achieve superior development and expansion not only in the numbers of customers but also in their asset base. Therefore for these organizations to blossom in the current highly competitive atmosphere they are obliged to take up strategies that would enable to positively respond and become accustomed to the transformations and challenges in their operational atmosphere. Some forces of transformation that have to a great extent predisposed the telecommunication business in Kenya include extreme competition, regulations and technological improvement (Letangule \& Letting, 2012). 
The Kenyan telecommunication industry has in recent past witnessed an increased competition which has forced the firms to not only re-think their strategies but also find new ways of expanding their businesses. Senior executives of telecommunication companies are faced with complex and important decisions as they content with major challenges in the industry one of which is the ever increasing competition. For an organization to achieve superior performance it has to lay in place approaches that position itself in market dominance.

Despite the fact that there is a positive trend in the growth of mobile telephony in Kenya, most of the operators are still struggling in their performance with an exception of Safaricom which dominates the market share at $65.4 \%$. Other operators such as Airtel, Orange and Equitel have a market share of $21.4 \%, 8.8 \%$ and $4.3 \%$ respectively while the new entrant in the industry Sema Moble Services has insignificant numbers of subscriptions that translates to zero per cent market share ( CA, 2018).

Despite the fact that a lot of studies have been done on the effect of strategic positioning on organizational performance most of those researches have focused on porter generic strategies and other competitive strategies such as strategic alliance, pricing strategies, costing and promotion positioning, technological advancement, customer segmentation and brand benefits. There seems to be a no research carried out on Best product strategic positioning as envisaged on the delta model and its effects on organizational performance. This study consequently seeks to establish the effect of Best product strategic positioning on organizational performance in the Kenya Telecommunication industry using strategic positioning as envisaged in the delta model strategy.

\section{$1.2 \quad$ Objectives of the Study}

The main objective of this study was to determine the effects of best product strategic positioning on organizational performance in the Kenyan telecommunication industry in Kenya. The specific objectives were:-

(i) To determine the effect of total customer solutions strategic positioning on organizational performance in the Kenyan telecommunication industry in Kenya.

(ii) To determine the moderating effect of the Government regulations on organizational performance in the Kenyan telecommunication industry.

\subsection{Research Hypotheses}

(i) $H_{o}:$ There is no statistical significant relationship between total customer solutions strategic positioning and organizational performance in the Kenyan telecommunication industry in Kenya.

(ii) $\boldsymbol{H}_{\boldsymbol{o}}$ : There is no statistical significant moderating effect of Government regulations on organizational performance in the Kenyan telecommunication industry.

\subsection{LITERATURE REVIEW}

\subsection{The Delta Model Theory}

The Delta Model is a strategy framework that was developed in the year 2003 by Dean Wilde, along with other members of Dean \& Company, and Arnoldo Hax of the MIT/Sloan School of Management. The most basic foundation of the model is that the authentic significance of whichever strategy is to accomplish client bonding. Bonding encompasses the attraction, gratification, and safeguarding of the consumer. Three extremely discrete strategic preferences for achieving these goals have been identified, as demonstrated in the triangle shaped figure labeled Figure 2.1 which was preferred to give a picture of the diverse strategic positioning alternatives not merely for the reason that it is an image representation that is simple to keep in mind, but also since it symbolizes the Greek alphabetical letter Delta, meaning transformation and change. These three strategic preferences for client bonding are referred to as the best product position strategy, the total customer solutions position strategy, and the system lock-in position strategy (Hax, 2010).

The Delta Model strategy visualizes client bonding as the real driving power. It believes that an organization is indebted to its clientele because they are the intimate storehouse of all the organization's deeds. Within management and consequently at the centre of strategy, inhabits the client we have to serve in a unique style if we anticipate to benefit from better-quality performance and this will be archived by attracting, gratifying and retaining the client, (Hax \& Wilde II, 2003).

The Delta Model strategy makes available an elaborate set of strategic positions that ensures there is high client bonding. There are three discrete strategic preferences which provide different approaches to achieving high degree of customer bonding. They include; 


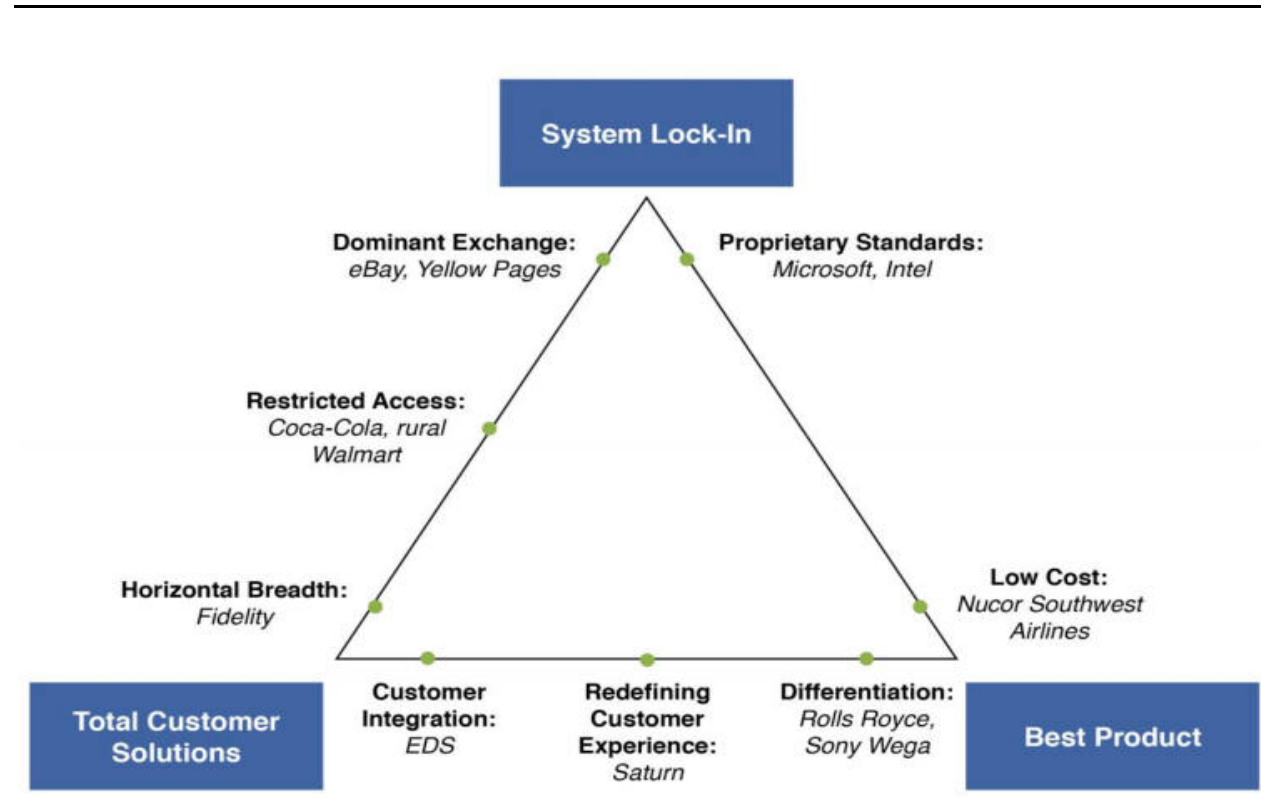

Figure. 2.1 Delta Model Triangle

Source: Reinventing Your Business Strategy by Arnoldo C. Hax, 2010.

\subsubsection{The Total Customer Solution position}

Here the main focus moves from the merchandize to the client. In this strategic option emphasize is placed on the client as opposed to the merchandize itself. It is a complete opposite of the best product position. Products economy here is not the focus; customer economics is. Performance is measured by customer market share or the share of the wallet. Product market share ceases to be a measure (Ceragioli \& Graeml, 2009).

The most fundamental aim of this strategy is to institute a strong symbiotic relationship between both parties. A kind of relationship that guides to a long-term participation that is unbreakable. This association is sure to produce a customer lock-in if it is rightly practised which is considered the highest measure of client bonding. This position proposes three types of sub positions which include customer integration, horizontal breadth, and redefining the customer experience, (Hax, 2010).

\subsubsection{Conceptual Framework}

Total Customer Solution

Complex web of connections Capabilities and Experience Competency and Knowledge Segmentation
Organizational Performance

- Growth of market share

- Increased customer satisfaction

- Increased customer loyalty

- Customer retention

- Increased profitability

- Development of new products

\section{Independent Variable}

Moderating Variable

Dependent Variable

Figure 2.2 Conceptual framework 


\subsection{Effects of Total Customer Solution on Organizational Performance}

In this research the focus will mainly on two aspects of total customer solution strategy that is customer integration and horizontal breath and how they affect organizational performance. According to Lau, Tang and Yam, (2010) there are few empirical research studies that have been done to investigate the achievement of a great product performance by use of product innovation enhanced by customer integration. Company size, market certainty and the type of industry constituted the three control variables that their research had. Their research was carried out in Hong Kong through a survey of 251 manufacturers and the aim of the study was to taste the relationship among the products innovativeness, product co-development, information sharing and performance. The findings of the research revealed that there is a direct and positive relationship between suppliers and customer integrations and product performance. After studying the findings of the research they recommended that the input of both the suppliers and customers should be considers by managers at an early age of design The managers too were notified of the information sharing with the suppliers which the research noted was important in product development . To directly arguments product performance and product innovation at the same time; the study suggested that an extensive effort on supplier and customer integrations should be made. From this study one notes that for any organization to achieve superior performance then it needs to pay closer attention to customer integrations.

Hax and Wilde II, (2001) noted that enhancing of the customers' ability to create their own economics value through provision of a coherent composition of products and services would ensure organization achieves a superior performance more than developing and marketing standardized and isolated products. They also found out development of an integrated supply chain that links an organization with its major suppliers and customers was of more benefits than having an inwardly or internal supply chain. Serving of organizational customers by putting together the entire set of corporate capabilities complemented by a good external party that would enhance its product offering would be of more benefit to the organization in terms of performance than focusing on competitors and limiting them.

When an organization performs various activities that were previously done by customers due to its higher effectiveness and efficiency to enrich customer economics we say that the organization has achieved customer integration, (Ceragioli \& Graeml, 2009). Despite customer spending more money in the short run, their total cost on the long run would be lower (Kotler 1994). It is therefore noted that a strong bonding between the organization and its customers and high switching cost is as a result of customer integration. This in turn has a great potential to increase organizational performance. The high commitment and common interest that emerge between the evolved parties would make customers integration approach to lead the organization in achieving a competitive edge and or advantages .

Customer's integration should not be mistaken for outsourcing which can create any competitive advantage through bonding and also provision of low costs of charge. The best example of an organization that had used customer integration successfully is the worldwide known Dell computers. This is because in addition to selling computers over the internet it is able offer other services which include but not limited to software installation and technical assistance to its customers worldwide,(Hax \& Wilde II, 2001). Another good example of customer's solution provided is the Electronic Data System (EDS). It positioned itself as an organization that has no interest in individual software or hardware companies and this made it to achieve a great prominence in the data processing industry. It provided the best solutions in the area of information needs regardless of the component origins. EDS ended up building a highly valued record through its delivery cost-effective and customized solution to each customer. It measured its success as a customer provider by how much it improved the customers' economics (Hax \& Wilde II, 1999).

Horizontal breath can enhance the performance of any organization that has decided to grow horizontally. A good example to demonstrate this according to Hax \& Wilde II, (1999) is MCI WorldCom which had an exemplary performance in terms of market share because it choose to expand horizontally in a range of related service for the targeted customer segment. It made the customer life easy by bundling the services together in order to reduce complexity for the client. A singled bill, one contact point for both sales and customer service and a more integrated highly utilized network were some of the benefits the customers got from the horizontal growth while the product remained the same. On the other hand MCI WorldCom had higher profits per customers and a great customers retention as its benefits. The new source of profitability at MCI WorldCom came as a result of adopting a strategy which was changing the rules of competition in the telecommunication industry.

When an organization provides a complete set of products and services with the aim satisfying the needs of customers in the best way; we say that total customer solution has been achieved through the horizontal breath. 
The maximization of customers economic and the strengthening of customers bonding through the integration and customization of wide scope of related products and services is the main goal of the horizontal breath positioning. This achievement of a bundle of products is of great importance as it has an ability to bring forth bonding opportunities. Horizontal breath positioning not only bundles products and services but also optimizes services by personalizing and integrating a related set of products so as to meet customer needs in the best way possible than when the customer goes to buy and use the products separately. From this; one notes that bundling is one of the best ways to create bonding opportunities (Hax \& Wilde II, 2001).

When as organization we want to ensure that we bond with our customers then we will need to learn from them their requirements, customize our offers to the customer's specific usages, have a single invoices and a single point of contact. Horizontal breath is more to do with a one-stop-shopping experience. It is more than the traditional volume discounts to the customers. It is about assisting the customers through incorporating and modifying a group of associated set of merchandise and services which in the end would make the customer enjoy enhanced value than if each element were to be bought and used independently.

According to Hax, (2010) Fidelity Company is one of the best companies that have fully embraced the use of horizontal breath positioning. It thrives in the stipulation of a complete set of products and services to its customers in the financial services industry which fulfils their complete set of requirements the provision to its clientele a single invoice, a single point of contact and understanding their requirement has made the organization to perform so well because of the bonding that has been achieved through the one stop-shop experience. Integrations and customization of a broad portfolio of related products has enhanced the scope of commercial relation through horizontal breath positioning. To offer benefits to the customer's horizontal breath goes an extra mile than supplying assets of products or services integrating and customizing them. Amazon.com is another good example of horizontal breath positioning. It uses data supplied by its own customers to provide them with a list of recommendations. Amazon.com has been very successful performance wise due to the use of horizontal breath positioning,(Jussani, Krakauer \& Polo, 2010).

Provision of a customized and integrated broad set of related products and services to customers which in turn improves their economics is what horizontal breath is all about (Hax \& Wilde II, 2001).Organization performance in terms of profitability is due to customers being referred a bundle of products and services that meets most of customers' needs. As the organization keeps customers close to its domain it will result in the increase in building a strong relationship with them. It is here that the bonding process between the organization and its customers to facilitated through a strong relationship which will definitely lead to the organization achieving competitive advantage because it becomes hard for the competitors to replicate the entire process (Piscopo, Joao, Thamhain, 2012).

Another example that can be considered as an example as a horizontal breath alternative is the Brazilian online leading retailer sub-marino.com.br. This company has its site offering a large selection of products that aim at satisfying a diversified range of customer's needs, along the line of a virtual department store offering books, CDS, DVDS, house hold appliances, baby items, toiletries and healthcare products even pet shop articles and musical instruments among others (Cozer, Toledo, Goldstein ,2008).

\subsection{Effects of Government regulations on organizational performance}

The government of Kenya regulates the telecommunication sector through the communication authority of Kenya. It is the only authority that regulates the entire communication sector in Kenya. The Kenya information and communications Act, 1998 is the one that established the authority in the year 1999. The authority was tasked with the responsibility of developing not only the information sector but also the communication sector too. Their scope included but not limited to telecommunications, electronic commerce, broadcasting, multimedia, postal and courier services. Some of the active role it was to play include country's frequency spectrum management and numbering resources, licensing of both the services and systems in the communications industry e-commerce development; approval and acceptance of equipments meant for communications, use of all the consumers and their rights within the communication ecosystem, providing a level playing ground to all the players within the sector, tarrif regulations for both the retail and wholesale; and finally activity monitoring of the licensees in order to enforce compliance of the license terms and conditions as well as the law, (CA, 2018). The above roles and responsibility of the CAK can either affect organizational performance positively or negatively.

\subsection{Organizational Performance}

Successful organizations are of great importance in any developing nation. They play a vital role in the day to day lives of citizens in these countries. They are the engine of political, social and economic development. 
Organizational performance is therefore is one of the most important variables in the management research and obviously the best indicator of any organizations success (Gavrea, Ilies \& Stegerean, 2011).

In this very competitive environment with a lot of threats from globalization any serious organization must seek to achieve a competitive edge over its competitors. This has been a bit difficult to most organizations because of challenges they face when it comes to the high competency requirements. So to measure organizational performance, one has to measure the actual outputs against the intended outputs i.e. the goals and objectives that had been earlier set (Alqudah, Osman \& Safizal, 2014).

According to Richard, Devinney, Yip \& Johnson (2009) organizational performance does a comparison of the three most important aspects of the company outcomes. This include return on assets, returns on investments and profits, which constitutes the financial performance, sales and market shares which constitutes product market performance and finally shareholder return. Organizational performance is viewed in terms of profits, which entails the comparison of the actual output weighed against the initial intended outputs. This entails various activities that have been put in place to establish the goals and aspirations of the entire organization and monitoring the progress that is been made towards achieving the targets that were set initially (Johnson et al; 2006).

\subsection{RESEARCH METHODOLOGY \\ 3.1 Research Philosophy}

Research philosophy is a significant part of research methodology. Research philosophy is categorized as ontology, epistemology and axiology. These philosophical approaches enable to decide which methodology should be adopted by the researcher and why, which is derived from research questions (Saunders, Lewis, \& Thornhill, 2009).

The approach challenges old notion of absolute and objective truth of knowledge in social sciences. Post-positivists argue that it is not possible to understand phenomenon through measurements (Graton \& Jones, 2010). The study adopted a post-positivism approach because the philosophical approach of natural scientist is observed in positivism as the work of natural scientist is based on observable social entity. Research strategy is approached on the basis of data collection and hypotheses development. These hypotheses will be tested and confirmed which can be used for further research. Furthermore, positivism works on quantifiable observations and accordingly statistical analysis is obtained (Saunders, Lewis, \& Thornhill, 2009).

\subsection{Research Design}

The study made use of descriptive survey design which involved collection and analysis of data from members of a populace so as to establish the present status of the subject of the study. Survey research is fundamentally a move towards to data collection that entails collecting data from large number of respondents.

Saunders, Lewis and Thronhill, (2009) in their book entitled Research methods for business students noted that due to the economical nature of a survey design was used because it permits the compilation of a huge volume of data from a substantial population. Through it a researcher can gather both quantitative and qualitative data that can be analysed quantitatively through the use of both inferential and descriptive statistics. The data collected through a survey design can be put to use not only in suggesting the possible reasons as to why certain relationship between variables exist but also bring into being models of the same relationships.

The use of a survey design furnished the researcher with additional control above the research procedure and whilst sampling was used to achieve findings that are reflective and representative of the entire population. A descriptive survey research was used because the study sought to get information that describes the existing phenomena by asking respondents about their perceptions, attitudes and value about how strategic positioning as envisaged in the delta model strategy is affecting their organizational performance.

\subsection{Population of the study}

This entails a complete set of cases from which a sample is taken. The target population for this particular study comprised 6,149 front office employees of licensed operators in the telecommunication industry in Kenya as at June 2016 Communication Authority of Kenya data; that is 4,574 from Safaricom Kenya Limited, 1,319 from Telkom Kenya Limited, 223 from Airtel Kenya Limited and 33 from Finserve Limited. This was done in the three cities and two municipalities in Kenya namely Nairobi, Mombasa, Kisumu, Nakuru and Eldoret. This cities and municipalities were purposively selected because they had certain characteristics relevant to the study such being the only ones with established telecommunication outlets shops from all the firms under study. They were also the most cosmopolitan cities and municipalities. The main goal of purposive sampling was to focus on particular 
characteristics of a population that are of interest. It provides the researcher with the justification to make generalizations from the sample that is being studied, (Kothari, 2004).

This study focused on the four major companies in the telecommunication sector who includes Safaricom, Airtel, Equitel and Orange. Sema Mobile services was not studied because at the time of writing this thesis it had insignificant number of subscriptions putting it at $0 \%$ market share this is as per the Communication Authority of Kenya first quarterly sector statistics report for the financial year 2016/2017 that is July-September 2016. The unit of analysis comprised of the organizations in the telecommunication sector as mentioned earlier and the target respondents were the customers facing 173 employees drawn from the operators in view of the fact that they directly transact daily in the management of the business and they are the very conversant with the effects of strategic positioning on the performance of their respective organizations.

\subsection{Sampling Frame}

A sampling frame as defined by Welman, Kruger and Mitchell, (2008) is a list of the source material or device from which a sample is drawn. It is a list of all those within a population who can be sampled, and may include individuals, households or institutions. A sampling frame may also refer to a list of elements from which the sample is actually drawn and is closely related to the population (Saunders, Lewis \& Thornhill, 2009). The study involved the four major players in the telecommunication industry in Kenya. Proportional stratified random sampling was used for this study. According to Kothari, (2004) stratified sampling technique was put to use to get a representative sample when and only when the population from which the sample is to be drawn doesn't constitute a homogenous group. When using the stratified sampling the population of the study is separated into numerous sub populations that are independently more harmonized than the total population. The population was stratified according to the telecommunication companies namely; Safaricom, Airtel, Equitel and Orange. From the four strata a sub-sample was determined for every section.

\subsection{Sampling size and sampling technique}

This section contains the sample size and the sampling techniques used in this study and the justification.

\subsubsection{Sampling size}

The sample size of the total number of respondents was found using the coefficient of variation. Nassiuma (2000) noted that in the majority of surveys or research, a coefficient of variation of less than thirty per cent and a standard error of less than five per cent is generally satisfactory. The Nassiuma's principle doesn't presume any probability distribution and is a steady measure of variability. Consequently, a standard error of $1.5 \%$ and a coefficient of variation of $20 \%$ was used in this study. To ensure low variability in the sample and also minimize the degree of error the lower limit for both coefficient of variation and standard error needs to be selected.

$$
n=\frac{N C^{2}}{C^{2}+(N-1) e^{2}}
$$

where; $\mathbf{C}$ is the coefficient of variation, $\mathbf{n}$ is the desired sample size, $\mathbf{e}$ is error margin and $\mathbf{N}$ is the accessible population. Thus taking $\mathrm{C}=20 \%$ and $\mathrm{e}=1.5 \%$

$$
n=\frac{6149 *(0.2)^{2}}{(0.2)^{2}+(6149-1) *(0.015)^{2}}
$$

$n=172.8$ approximately $=173$. Therefore $n$ is 173 respondents.

The total sample size of 173 respondents was determined. Allocation was done to each strata using proportional stratified random sampling. Proportionate stratification requires that the sample size of every stratum to be in proportion to the population size of the stratum. The following is the equation that was used in the determination of the strata sample size:

$\mathrm{n}_{\mathrm{h}}=\left(\mathrm{N}_{\mathrm{h}} / \mathrm{N}\right) * \mathrm{n}$

Where $\mathrm{n}_{\mathrm{h}}$ represents the sample size for stratum $h, \mathrm{~N}_{\mathrm{h}}$ represents the population size for stratum $h, \mathrm{~N}$ represents the total population size, and finally $\mathrm{n}$ represents total sample size.

Table 3.1 Sample size Determination

\begin{tabular}{lcc}
\hline Telecom Firms & Customer facing Staff Population & Sample Size \\
\hline Safaricom & 4574 & 129 \\
Airtel & 223 & 6 \\
Orange & 1319 & 37 \\
Equitel & 33 & 1 \\
Total & 6149 & 173 \\
\hline
\end{tabular}

Source: Communication Authority of Kenya (2016). 


\subsubsection{Sampling technique}

Simple random sampling technique was used so as to make it possible for all in the target population to have an equal likelihood of inclusion.

The individual respondents were selected by way of simple random sampling once the population had been rightly stratified and the sample size for every stratum correctly determined. This was done by selecting the staff from each stratum working in the respective telecommunication firms. This procedure is favoured for the reason that it guaranteed representative treatment of all elements being considered in the study.

\subsection{Data Collection Instruments}

Data for this study was collected using a questionnaire. The questionnaires were self-administered by the researcher with the assistance of trained research assistants. The researcher and the research assistants assured the respondents that their responds will be treated with a high degree of confidentiality and also that their anonymity will be safeguarded. The instruments were used to collect data on demographic variables such as occupation, marital status, education, gender, age and to measure the effects of strategic positioning on organizational performance of the Kenyan telecommunication industry. The researcher and the research assistants made prior appointments with the various managers of the telecommunication outlets in the purposively selected cities and municipalities to enable the distributions of the questionnaires to be smooth.

Data was collected over a period of one month for the duration of working hours which is from 9.00am to $4.00 \mathrm{pm}$, Monday all the way through Friday. The total quantity of items that measured the criterion variable were 29 and were operationalized using a fire-point Likert scale, ranging from ( $1=$ Strongly disagree $)$ to $(5=$ Strongly agree $)$. The scale was helpful in determining the strength of respondents' responses on these items. The items were constructed based on the delta model strategic positioning and its effect on organizational performance. The questionnaires were distributed equally to all cites and municipalities apart from the capital city which received slightly more questionnaires. Each of the five trained research assistants took 33 questionnaires with the exception of the one who went to the Nairobi city who took 41 questionnaires.

Table 3.2 Distributions of questionnaires in the Cities and Municipalities

\begin{tabular}{llllll}
\hline City/Municipality & Safaricom & Airtel & Orange & Equitel & $\begin{array}{l}\text { Total } \\
\text { questionnaires } \\
\text { per research } \\
\text { assistant }\end{array}$ \\
\hline Nairobi city & 29 & 2 & 9 & 1 & 41 \\
Mombasa city & 25 & 1 & 7 & 0 & 33 \\
Kisumu city & 25 & 1 & 7 & 0 & 33 \\
Nakuru municipality & 25 & 1 & 7 & 0 & 33 \\
Eldoret municipality & 25 & 1 & 7 & 0 & 33 \\
\hline TOTAL & $\mathbf{1 2 9}$ & $\mathbf{6}$ & $\mathbf{3 7}$ & $\mathbf{1}$ & $\mathbf{1 7 3}$
\end{tabular}

\subsection{Data Collection Procedures}

Data was collected using questionnaire that were submitted to a random sample of employees as per the stratified sample. The data was collected in two month during working hours. Before proceeding to the field, a permit for carrying out the research was obtained from Jomo Kenyatta University of Agriculture and Technology and also from National Commission for Science Technology and Innovation (NACOSTI). With granted authority, permission was sought from the respective firm's management to conduct the study at their entities. The respondents were requested to fill the questionnaire and return them to the researcher. The participants were guaranteed that any data that the researcher collected would be treated with utter confidentiality and used only for academic purposes.

\subsection{Pilot Test}

A pilot test was performed to distinguish limitations in design and instrumentation and to present substitute statistics for mixture of probability sample. The instruments were pilot tested in four firms in Narok County. The 
rationale of a pilot study was to identify the mistakes and bias in the design and improve the final instrument to be able to collect the correct data for the analysis. The county was chosen because it is likely to include subjects with similar characteristics as those who were interviewed in the final or actual interview.

The volume of the pilot group possibly varies from 25 to 100 subjects, depending on the techniques experienced, but respondents do not have to be statistically selected, (Cooper \& Schindler, 2011). A purposively selected sample of 25 respondents from the same categories chosen in Narok County with similar characteristics was used to explore any errors in format, wording or design of the instrument.

\subsubsection{Validity of the study instruments}

The study attempted to make certain that the findings of the study was not only valid and but also very reliable. Validity is the degree to which the test-items determine what they purport to do. The instrument's content validity was considered using expert judgment by the faculty academic staff in the department of Business Administration, in Jomo Kenyatta University of Agriculture and Technology.

The study used Kaiser-Meyer-Olkin Measure of Sampling Adequacy in testing the validity of the research instrument. The instruments were considered valid if the KMO value was more than 0.4. Technically, KMO which ranges from 0 to 1 , should be higher than the factor loading of 0.4 to be considered as an acceptable value for a good factor analysis and the Barltlett's test of sphericity significant level must be smaller than 0.05 (Pallant, 2005). Here items on the questionnaire are checked against the objectives of the study so as to ensure that there is adequate coverage of items. The researcher also checked to ensure that face validity was attained by using experts to summarise the question items. The results of validity were presented on Table 3.3.

Table 3.3: KMO and Bartlett's Test

\begin{tabular}{ccc}
\hline Objectives & Bartlett's Test of Sphericity & Sig. \\
& Approx. Cheyer-Olkin & Chi-Square \\
Adequacy. & & \\
\hline
\end{tabular}

\begin{tabular}{lccc} 
Total Customer Solution & .761 & 592.150 & .000 \\
\hline Government Regulations & .777 & 380.473 & .000 \\
\hline
\end{tabular}

The results show that all the KMOs were more than 0.7 for the group of independent variables. This indicates that the research instrument was valid and hence could be used effectively in data collection and hence analysis. Technically, KMO which ranges from 0 to 1, should be higher than the factor loading of 0.4 to be considered as an acceptable value for a good factor analysis and the Barltlett's test of sphericity significant level must be smaller than 0.05 (Pallant, 2005).

\subsubsection{Reliability of the study instruments}

Reliability on the other hand refers to the consistence of a score form one occasion to the next. The pilot test data was used to establish the reliability of the instrument. This was accomplished using Cronbach's alpha procedure, which is appropriate for establishing both inter-item and inter case consistency. This procedure required a single administration of a test and it is the most appropriate type of reliability for measures that contain a range of possible answers for each item of an instrument (Kathuri \& Pals, 1993). A minimum reliability coefficient of 0.7 was used as a bench-mark as recommended by Kothari (2004).

The pilot test data was used to establish the reliability of the instrument. This was accomplished using Cronbach's alpha procedure, which is appropriate for establishing both inter-item and inter case consistency. This procedure required a single administration of a test and it is the most appropriate type of reliability for measures that contain a range of possible answers for each item of an instrument (Kathuri \& Pals, 1993). A minimum reliability coefficient of 0.7 was used as a bench-mark as recommended by McClelland, (1961). Efforts were made to ensure the research instruments are reliable and valid. The study also used secondary data which involved use of financial statement analysis for the last five years. 
Table 3.4 Reliability Statistics

\begin{tabular}{lll}
\hline Items & Cronbach's Alpha & No. of Items \\
\hline Total Customer Solution & .877 & 6 \\
Government Regulations & .876 & 5 \\
\hline
\end{tabular}

From the results presented in Table 3.4 it shows that the two factors are reliable since the reliability values were more than 0.7. These results corroborates findings by Saunders Lewis and Thornhill (2009) and Christensen, Johnson and Turner (2011) who stated that scales of 0.7 and above, indicate satisfactory reliability. Based on these recommendations, the statements under each of the two variables of this study were concluded to have adequate internal consistency, therefore, reliable for the analysis and generalization on the population.

\subsection{Data analysis and presentation}

Data analysis constituted the various steps that include the coding of responses, cleaning, screening the data and the selection of the appropriate analysis strategy. Identification, classification and assignment of the numeric or character symbol to data constituted the pre-coding of the responses. Inconsistency checks and missing responses were taken through the process of cleaning and screening data. The preliminary data analysis including frequency, mean and standard deviation was done using statistical package for social sciences (SPSS).

Thus both descriptive and inferential analysis was required for this study. Descriptive analysis involved the calculation of standard deviation, mean and frequency distribution which are helpful to classify distinctions amongst groups. Inferential analysis assisted in understanding cause-effect relationships among the study variables.

Various statistical tests were computed to determine the degree association and/or interrelationships among the dependent variable (Organizational performance) and the independent variables (Strategic positioning). Correlation and regression analyses were the main statistical techniques that were used in this study to investigate the hypothesed relationships in the study. The level of significance of $5 \%$ was used in all the measurements in the study. Correlation analysis gives a picture of the strength of linear relationship among two variables. Correlation coefficients run from -1 to +1 . Correlation coefficients close to -1 show a strong inverse relation whilst a coefficient close to +1 denotes a strong direct relation. Mathematically, a correlation between two variables $\mathrm{X}$ and $\mathrm{Y}$ is given by:

$$
r=\sum_{-}(x-\bar{x})(y-\bar{y}) / \sqrt{\sum(x-\bar{x})^{2} \sum(y-\bar{y})^{2}}
$$

Where $x, y$ $\mathrm{r}=$ Correlation coefficient

\subsection{RESULTS}

4.1 Effects of Total Customer Solution strategic positioning on Organizational Performance in the Kenyan telecommunication industry

The study sought to establish the effect of total customer solution strategic positioning on organizational performance in the Kenyan telecommunication industry. The respondents were asked to indicate the extent to which they agreed or disagreed with the various statement items used to explain the relationship between the two variables. The results were presented in

Table 4.1 
Table 4.1: Descriptive Statistics on the Effects of Total Customer Solution on Organizational Performance

\begin{tabular}{llllllll}
\hline ITEMS & SD & D & U & A & SA & Mean $\begin{array}{l}\text { Std. } \\
\text { Dev }\end{array}$ \\
\hline
\end{tabular}

Our firm has established a complex network of associations with the customer consequently enhancing their capability to do business and use our products

$$
\begin{array}{lllllll}
1.4 \% & 18.1 \% & 3.5 \% & 48.6 \% & 28.5 \% & 3.85 & 1.073
\end{array}
$$

We are a collection of competencies and combined knowledge that can be transmitted successfully to the customers

We have integrated and customized a relate set of products and services to assist our customers

Where we don't have the capabilities we $6.3 \% \quad 17.4 \% \quad 20.8 \% \quad 22.2 \% \quad 33.3 \% \quad 3.59$ contact our complimentary

Our capabilities dwell not only internally in

$$
\begin{array}{llllll}
5.6 \% & 4.9 \% & 25.0 \% & 31.3 \% & 33.3 \% & 3.82
\end{array}
$$
the firm but also in the whole network of

\begin{tabular}{|c|c|c|c|c|c|c|}
\hline $.7 \%$ & $11.1 \%$ & $12.5 \%$ & $47.2 \%$ & $28.5 \%$ & 3.92 & .957 \\
\hline $6.3 \%$ & $17.4 \%$ & $20.8 \%$ & $22.2 \%$ & $33.3 \%$ & 3.59 & 1.281 \\
\hline $5.6 \%$ & $4.9 \%$ & $25.0 \%$ & $31.3 \%$ & $33.3 \%$ & 3.82 & 1.120 \\
\hline $.7 \%$ & $10.4 \%$ & $27.1 \%$ & $31.9 \%$ & $29.9 \%$ & 3.80 & 1.008 \\
\hline
\end{tabular}
connected firm strategic assets in holding with customers

The results presented on Table 4.1 shows that most of the respondents $59.7 \%$ agreed with the statement $29.2 \%$ strongly agreed that the firm had established a complex network of associations with the customers consequently enhancing their capability to do business and use the products. $1.4 \%$ of the respondent's disagreed with the statements. This implies that the firm has an established complex network in which they respond to their customers by offering total solutions. This is confirmed by the mean value of 4.17 and a standard deviation of .648 showing that majority of the respondents agreed with the statement.

It was also established that most of the respondents $48.6 \%$ agreed with the statement that the firm has a collection of competencies and combined knowledge that is transmitted successfully to the customers. Only $28.5 \%$ strongly agreed while $18.1 \%$ disagreed with the statement. This indicates that majority of the respondents with a mean of 3.85 and a standard deviation of 1.073 agreed that the firms have competent and knowledgeable staff for providing total customer solution.

The findings of the study also indicated that most of the respondents $47.2 \%$ agreed, followed by $28.5 \%$ who strongly agreed with the statement that the firm has integrated and customized a related set of products and services to assist their customers. Only $11.1 \%$ disagreed with the statement. The results also show that with a mean response of 3.92 and a standard deviation of .957 . Majority of the respondents agreed with the statement which implies that the firms have an integrated system that provides total customer solution.

It was also noted that $33.3 \%$ of the respondents strongly agreed that firms do contact their complimentary in areas where they feel they lack the capability to handle their customers' needs. This was followed by $22.2 \%$ who agreed with the statement while only $17.4 \%$ strongly disagreeing with the statement. This was further confirmed by the mean value of 3.59 and a standard deviation of 1.281 . The results indicates that firms ensure they are providing 
total customer solutions by partnering with other firms to be able to ensure customers receive their services where the firm lacks capacity and capability.

It was also important to establish whether the respondents felt that their capabilities dwell not only internally in the firm but also in the whole network of connected firm to meet their customers' needs. The results show that most of the respondents $31.3 \%$ agreed with the statement, $33.3 \%$ strongly agreed while only $5.6 \%$ strongly disagreed with the statement. The mean response was 3.82 while the standard deviation was 1.120 indicating that majority of the respondents agreed with the statement. This implies that the firms do not only consider their internal capabilities to satisfy their customers' needs but they also consider external network capabilities of connected firms in ensuring that they offer total customer solutions.

The results also indicated that the firms have a network of companies that are key strategic assets in holding customers. The findings show that majority of the respondents $29.9 \%$ strongly agreed with the statement, $31.9 \%$ agreed while only $10.4 \%$ disagreed with the statement. This shows that in order to offer total customer solutions by the firms they have created networks with other companies. This is also confirmed by the high mean value of 3.80 and the small standard deviation of 1.008 which shows that most respondents agreed that they ensure totals customer satisfaction by creating good networks with other companies that have key strategic assets for satisfying the customers.

\subsection{Correlation analysis for Total Customer Solution strategic positioning and organizational performance.}

The results were further analyzed to establish the relationship between the variables. This was done using the Pearson's correlation (r) which was used to test the significance of the relationship between Total Customer Solution strategic positioning and Organizational Performance. The relationship was considered to be significant if the p- value was $<$ than 0.05 . The results were presented in Table 4.8.

Table 4.2: Pearson's Correlation analysis on the Effects of Total Customer Solution strategic positioning on Organizational Performance.

Organizational Performance

\begin{tabular}{lll}
\hline & Pearson Correlation & $.367^{* *}$ \\
Total Customer Solution & Sig. (1-tailed) & .000 \\
& $\mathrm{~N}$ & 144 \\
$*$ * Correlation is significant at the 0.05 level (1-tailed). & \\
\hline
\end{tabular}

From the results on Table 4.2, it is noted that the relationship between the total customer solution and organizational performance was weak but positive $(r=0.367)$ and it was very significant $(p<0.05)$. This implies that the adoption of the total customer solution as a positioning strategy by the Kenyan telecommunication companies has a very significant effect on the performance of the organization. The study finding were in agreement with the findings of Riasat et al (2015) which revealed that strategic positioning and strategic customer relationship management have a strong, positive and significant association with organizational performance and that customer knowledge competence also have significant association with organizational performance. The result is also in agreement with that of Hax and Wilde (1999), which found out that a car dealer known as Saturn which abandoned the best product strategic positioning to embrace the total customer solutions strategic positioning. The decision by Saturn to focus on customers comfort and meeting their needs resulted in an overwhelming customer response, creating the highest customer satisfaction rate in the industry which in turn resulted in great organizational performance.

\subsection{Regression analysis and hypotheses testing}

The study further sought to establish the magnitude of the relation which is defined by $\mathrm{R}$ squared and develop a regression model in the presence of government regulations as a moderating factor. The analysis was first done by considering the direct relationship between independent variables and then using the step wise regression analysis the moderating factor (government regulations) was introduced to examine the effect on the model. The study sought to test the four hypotheses using the ANOVA results.

From the analysis of the collected data $\mathrm{R}$ represents the co-efficient of correlation to test for the degree of the relationship; $\mathrm{R}^{2}$ represents the co-efficient of the determination to test for the extent to which two variables are 
correlated, Sig. value in the ANOVA table represents the significance of the relationship between two variables while the co-efficient table represents the model establishing the relationship between variables and their significances in the model. The results were thereafter supported by previous findings of scholars in the related field to justify the results of the study.

\subsubsection{Regression Model summary effect on the Total customer solution strategic positioning on organizational performance}

Hypothesis $\boldsymbol{H}_{\boldsymbol{O}}$ : There is no significant relationship between total customer solution strategic positioning and organizational performance in the Kenya telecommunication industry.

Table 4.3: Model summary on simple regression for the total customer solution $\quad$ strategic positioning before and after moderation.

\section{Sig}

\begin{tabular}{cccccc} 
Model & $\mathrm{R}$ & R Square & Adjusted R Square & $\begin{array}{c}\text { Std. Error of the } \\
\text { Estimate }\end{array}$ \\
\hline 1 & $.367^{\mathrm{a}}$ & .135 & .129 & .775 & $.000^{\mathrm{a}}$ \\
2 & $.431^{\mathrm{b}}$ & .186 & .174 & .755 & $.000^{\mathrm{b}}$ \\
\hline
\end{tabular}

a. Predictors: (Constant), Total customer solutions

b. Predictors: (Constant), Total customer solutions, government regulations

The model summary Table 4.3 provides important information about regression analysis for the second hypothesis before and after moderation.

The correlation coefficient $(\mathrm{R})$ value of 0.367 before moderation indicates the existence of a weak but positive relationship between total customer solution strategic positioning and organization performance. The coefficient of determination $\left(\mathrm{R}^{2}\right)$ value of 0.135 explains the proportion of variation in total customer solution strategic positioning and organizational performance is influenced by a $13.5 \%$ change in total customer solution strategic positioning. The value of $\mathrm{R}^{2}=0.135$ shows that Total customer solution strategic positioning is a predictor of organization performance.

The result shows that the goodness of fit for the regression between total customer solution strategic positioning and organization performance was satisfactory since the $\mathrm{p}$ value was less than 0.05 i.e. $\mathrm{p}=0.000$ indicating that the relationship between the two variables is statistically significant. The moderated model (2) was also very significant since $\mathrm{R}^{2}=0.186$ and $\mathrm{p}=0.000$ indicating that a unit change in total customer solution strategic positioning influences organization performance by $18.6 \%$. This shows that with appropriate government regulations, total customer solution strategic positioning enhances organizational performance of telecommunication industry.

The "Standard error of estimate" indicates that, on average, observed organizational performance deviate from the predicted regression line by a score of 0.775 and 0.755 before and after moderation respectively.

\subsubsection{Analysis of Variance for the total customer solution strategic positioning}

The study also sought to establish the variance between the means of the variables defined by the F- statistic. The model was tested to establish whether it is a good predictor of the relationship between the variables or not. The results were presented in Table 4. 10. 
Table 4.4: Summary of analysis of variance for customer solutions

\begin{tabular}{lllllll} 
Model & & Sum of Squares & Df & Mean Square & F & Sig. \\
\hline 1 & Regression & 13.326 & 1 & 13.326 & 22.170 & $.000^{\mathrm{a}}$ \\
& & & & & \\
& Residual & 85.356 & 142 & .601 & & \\
& Total & 98.682 & 143 & & 16.093 & $.000^{\mathrm{b}}$ \\
\hline 2 & Regression & 18.340 & 2 & 9.170 & & \\
& & & & & \\
& Residual & 80.342 & 141 & .570 & & \\
& Total & 98.682 & 143 & & & \\
\end{tabular}

a. Predictors: (Constant), Customer Solutions

b. Predictors: (Constant), Customer Solutions , Government Regulations

c. Dependent Variable: performance

The F statistic was significant at 5\% level of significance implying that the model fits well. The results are shown in Table 4.4. The study also established the model fitness by comparing the F-calculated and F-critical values. The results for F calculated are in Table 4.4. The F-Critical, $F_{0.05,1,142}$ was 3.84. Since F calculated, 22.170, was greater than F-Critical, the study concluded that the model fits well. This is further supported by a p-value of 0.000 which is significant at 5\% level of significance implying that the model fits well. The results in Table 4.5 present the regression model coefficients.

Therefore, hypothesis two which states that there is no significant relationship between total customer solution strategic position and organizational performance in the Kenyan telecommunication industry was rejected both before and after moderation and concluded that total customer solution strategic option influenced organizational performance.

Table 4. 5. Summary of regression Coefficients for total customer solution

\begin{tabular}{|c|c|c|c|c|c|c|}
\hline & & \multicolumn{2}{|c|}{$\begin{array}{l}\text { Unstandardized } \\
\text { Coefficients }\end{array}$} & \multirow{2}{*}{$\begin{array}{l}\text { Standardized } \\
\text { Coefficients } \\
\text { Beta }\end{array}$} & \multirow[b]{2}{*}{$\mathrm{t}$} & \multirow[b]{2}{*}{ Sig. } \\
\hline \multicolumn{2}{|c|}{ Model } & $\mathrm{B}$ & Std. Error & & & \\
\hline \multirow[t]{2}{*}{1} & (Constant) & 2.688 & .314 & & 8.560 & .000 \\
\hline & Total customer solution & .375 & .080 & .367 & 4.708 & .000 \\
\hline \multirow[t]{3}{*}{2} & (Constant) & 2.247 & .340 & & 6.610 & .000 \\
\hline & Total Customer Solution & .270 & .085 & .264 & 3.160 & .002 \\
\hline & Government Regulation & .231 & .078 & .248 & 2.966 & .004 \\
\hline
\end{tabular}

a. Dependent Variable: performance

The regression coefficients were computed using the stepwise method and used to develop the simple regression model. The value of the intercept better indicates the value of organizational performance when all the explanatory variables are zero is 2.688 before moderation and 2.247 after moderation by government regulations. The estimated coefficient for the total customer solution strategic positioning is 0.375 and the p-value is 0.000 which is less than 0.05 which in turn indicates that the effect of total customer solution strategic positioning on organizational performance in the Kenyan telecommunication industry is statistically significant.

The results show that total customer solution strategic positioning contributes significantly to the model since the $\mathrm{p}$-value is less than 0.05 before and after moderation. The finding imply that one positive unit change in the total customer solution strategic positioning leads a 0.375 change in the performance of the telecommunication industry in Kenya. This confirms the positive effect of total customer solution strategic positioning on the organizational 
performance of the telecommunication industry. The study finding were in agreement with the findings of Riasat et al. (2015) which revealed that strategic positioning and strategic customer relationship management have a strong, positive and significant association with organizational performance and that customer knowledge competence also have significant association with organizational performance.

Simple regression model for relationship between total customer solution strategic positioning and organizational performance is as follows:-

$O P=\beta 2+\beta 2 T C S+e$

$\mathrm{OP}=2.688+0.375 \mathrm{TCS}+0.314$

Moderated simple regression model

$$
\begin{gathered}
O P=\beta 0+\beta 2 T C S+\beta 2 G R+e \\
O P=2.247+0.270 T C S+0.231 G R+0.340
\end{gathered}
$$

\subsection{DISCUSSION}

\subsection{Effect of Total Customer Strategic Positioning on Organizational Performance}

The study also revealed that the total customer solution strategic positioning had the greatest influence in the organizational performance of the telecommunication industry in Kenya. The findings of the study revealed that total customer solution strategic option had a significant coefficient. This implies that total customer solutions strategic option had a positive significant effect on organization performance.

\subsection{Effect of Government Regulations on Organizational Performance}

The findings of the research revealed that a change in the government regulations had a positive and very significant effect on the performance of the telecommunication companies in Kenya. This is revealed by the results which show that there is a weak, positive correlation which is significant.

\subsection{Conclusion}

The study also concludes that the decision by most telecommunication companies to use total customer solution strategic positioning is appropriate as it enhances organizational performance. Consequently managers in this telecommunication firms need to pay special attention to the total customer solution strategic positioning strategy by providing their customers with the best solutions to their needs. The study finding were in agreement with the findings of other scholars which revealed that strategic positioning and strategic customer relationship management have a strong, positive and significant association with organizational performance and that customer knowledge competence also have significant association with organizational performance. The result is also concludes that the decision to focus on customers comfort and meeting their needs resulted in an overwhelming customer response, creating the highest customer satisfaction rate in the industry which in turn resulted in great organizational performance.

Finally the study concluded that a change in the government regulations has a positive and very significant effect on the performance of the telecommunication companies in Kenya. This shows that with appropriate government regulations, best product, total customer solution and system lock-in strategic positions will enhances organizational performance of telecommunication industry. This implies that a change in the government regulations has a positive and very significant effect on the performance of the telecommunication companies in Kenya. This is in agreement with other studies which noted that policy and regulatory framework led to enhancement in organizational performance by creating a level of playing field for organizations. Policy and regulatory framework also led to improvement in transparency, openness, improved ethical standards, impartiality as well as improving decision making.

\subsection{RECOMMENDATIONS}

\section{(i) Recommendation for managers}

The study recommends to managers that for any effective organization performance to be achieved through the use of total customer solution strategic positioning then managers need to ensure that their firms have established a complex network of associations with the customers, consequently enhancing their capability to do business and use our products, they should be a collection of competencies and combined knowledge that can be transmitted successfully to the customers, they should have integrated and customized a related set of products and services to assist their customers better than would have been if each component was to be purchased and used separately (One stop shop), they should contact their complimentors where they don't have the capabilities in order to serve 
their customers well, they should have their capabilities dwell not only internally in the firm but also in the whole network of connected firms and finally they should have a network of companies that are a key strategic asset in bonding with customers.

\section{(ii) Recommendation for government policy makers}

This study recommends that for the government regulation to be effective they should be efficient in enforcing regulations on unethical business behaviour, efficient at penalizing firms as a result of unethical business behaviour, should fulfil its objective of preventing the consumers from unethical business practices, should efficient at conducting appropriate tests and ensuring compliance with the approved specifications for the effective control of quality and finally they should be able to prevent dominance of the industry by one player.

\section{(iii) Areas for Further Research}

Thus the study recommends that other researchers to focus their research on the following:

a) The research should be done on other industries in Kenya such us manufacturing industries, the aviation industry, transport industries, banking industries etc. These comparative studies are important.

b) In the sample distribution researchers should use other sampling methods other than the proportionate sampling used in this research and see what effect it will have on the final results.

c) The same study should be done in other countries in order to draw a comparative analysis of the finds.

\section{REFERENCES}

AlQudah, M.K., Osman, A., \&Safizal, M.A. (2014). Crtical success factors of organizational performance: A study of small and medium enterprises in Jordan, Journal of Humanities and social science, 19(6), 53-57

Ceragioli, F., \& Graeml, A. R. (2009). Entry Mode Influence On Strategic Positioning: Analysis Of Two Telephone Operators In Brazil. Journal of Operations and Supply Chain Management, 2(1), 104-114.

Chelimo, C. (2012), Positioning Strategies used by firms in the telecommunications industry in Kenya. Unpublished thesis.

Christensen, L. B., Johnson, B., Turner, L. A., \& Christensen, L. B. (2011). Research methods, design, and analysis.

Cooper, R.D. \& Schindler, S.P, (2011). Business Research Methods, Singapore: McGraw Hill.

Cozer, M. T. D. S., Toledo, G. L., \& Szafir-Goldstein, C. (2008). Inter-organizational ties and total customer solution strategic positioning from Delta model: a research about dyad supplier-client on B2B. RAM. Revista de Administração Mackenzie, 9(7), 163-187.

Diskaya, F., Emir, S., \& Orhan, N. (2011). Measuring the technical efficiency of telecommunication sector within global crisis: comparison of G8 countries and Turkey. Procedia-Social and Behavioral Sciences, 24, 206218.

Djiofack-Zebaze, C., \& Keck, A. (2009). Telecommunications services in Africa: The impact of WTO commitments and unilateral reform on sector performance and economic growth. World Development, 37(5), 919-940.

Gavrea, C., Ilies, L., \& Stegerean, R. (2011). Determinants of organizational performance: The case of Romania. Management \& Marketing, 6(2), 285.

Gratton, C., \& Jones, I. (2010). Research methods for sports studies. Routledge.

Hax, A. C. (2010). The delta model: reinventing your business strategy. Springer Science \& Business Media.

Hax, A. C., \& Wilde II, D. L. (1999). The Delta model: adaptive management for a changing world. MIT sloan management review, 40(2), 11.

Hax, A. C., \& Wilde, D. L. (2003). The delta model-a new framework of strategy. Journal of Strategic Management Education, 1(1), 1-21.

Hax, A., \& Wilde II, D. (2001). The Delta Model-discovering new sources of profitability in a networked economy. European Management Journal, 19(4), 379-391.

https://ca.go.ke/wp-content/uploads/2018/10/Quarter-Four-sector-statistics-report-for-the-Financial-Year-201718.pdf

Iversen, G. R., \& Gergen, M. (2012). Statistics: The conceptual approach. Springer Science \& Business Media.

Johnson, G., Richard, P.J, Devinney, T.M., \& Yip, G.S., (2006), Measuring organizational performance: Towards Methodological Best Practice. Journal of Management, 35, 718 - 804.

Jussani, A. C., de Castro Krakauer, P. V., \& Polo, E. F. (2010). Reflections on Blue Ocean strategy: a comparison with Ansoff's, Porter's, and Hax and Wilde's Strategies. Future Studies Research Journal: Trends and Strategies, 2(2), 17-37. 
Kathuri, J.N. \& D.A. Pals, (1993), "Introduction to Education Research”. Educational Media Centre, Egerton University, Njoro.

Kothari, C.R.,(2004). Research methodology: methods and Techniques. India:New Age International (P) Ltd.

Kotler, P. \& Keller, K.L. (2012). Marketing Management (14ed. England: Pearson Education Limited.

Kotler, P. (1994). Marketing management, analysis, planning, implementation, and control, Philip Kotler. London: Prentice-Hall International.

Lau, A. K., Tang, E., \& Yam, R. (2010). Effects of supplier and customer integration on product innovation and performance: Empirical evidence in Hong Kong manufacturers. Journal of Product Innovation Management, 27(5), 761-777.

Letangule, S.L. \& Letting, N., (2012), "Effect of innovation strategies on performance of firms in the telecommunication sector in Kenya," International journal of Management and Business Studies, 2(3), $75-78$.

McClelland, D.C. (1961). "The Achieving Society”. NY: Van Nostrand.

Mokaya, S.O. Kanyagia, C.P, \& Wagoki, J. (2012). Market positioning and organizational performance in the Airlines Industry in Kenya, International Journal of Arts and Commerce, 1(4), 121 - 132.

Nassiuma, D. K. (2000). Survey Sampling: Theory and Practice, Nairobi.

Pallant, J. (2005). SPSS survival manual: A step guide to data analysis using SPSS for Windows version 12.

Piscopo, M. R., do Nascimento João, B., \& Thamhain, H. J. (2012). The value net, the Delta model, and the aeronautics industry. Revista Ibero-Americana de Estratégia, 11(2), 5.

Riasat,F.,Naisar,Q.A., Haider,S., Gill,S.S., Khadim, F.M., Noreen, S.(2015), Relationship among strategic positioning, strategic customer relationship management and organization's performance. International Journal of management research and emerging science, 5(1), 47-63

Richard, P. J., Devinney, T. M., Yip, G. S., \& Johnson, G. (2009). Measuring organizational performance: Towards methodological best practice. Journal of management, 35(3), 718-804.

Saunders, M., Lewis, P., \&Thornhill, A.,(2009) Research methods for business students, Eng-land: Pearson Education Limited.

Welman, J. C., \& Kruger, S. J., \& Mitchell, B. (2008). Research Methodology . Cape Town. 